\title{
Pre-slaughter bodyweight and daily gains in mink are independent of the housing system
}

\author{
N. Święcicka\# \& H. Bernacka \\ University of Technology and Life Sciences, Bydgoszcz, Faculty of Animal Breeding and Biology, Department of Sheep, \\ Goat and Fur Animal Breeding, Kordeckiego 20, 85-225 Bydgoszcz, Poland
}

(Received 8 December 2016; Accepted 15 February 2017; First published online 13 March 2017)

\author{
Copyright resides with the authors in terms of the Creative Commons Attribution 4.0 South African License. \\ See: http://creativecommons.org/licenses/by/4.0/za \\ Condition of use: The user may copy, distribute, transmit and adapt the work, but must recognize the authors and the South African \\ Journal of Animal Science.
}

\begin{abstract}
The research hypothesis assumed that the size of the cage affects bodyweight after weaning and prior to slaughter and, as a consequence, mean daily bodyweight gains in individuals of both sexes. The study was conducted from 2014 to 2015 at one of the private mink farms in Poland. In total, 800 brown mink were used as the object of research (400 animals in a given year). In each year, the animals were divided into two equal-sized groups, in accordance with their housing system. The first group included animals living in single-storey cages and the second group lived in two-storey cages (i.e. cages with an upper level added). The animals were weighed after weaning and before slaughter. Based on these data the mean daily bodyweight gains were calculated. The research hypothesis was rejected. The conclusion of the analysis of variance is the statement that the cage size did not affect either the animals' bodyweight or their mean daily weight gains. The differences in these results, however, were observed in individuals of different sexes. Males were significantly heavier than females and showed higher daily weight gains. High and positive correlation coefficients were also noticed between bodyweight prior to slaughter and mean daily weight gains.
\end{abstract}

Keywords: Bodyweight gains, cage type, mink

\# Corresponding author: swiecicka@utp.edu.pl

\section{Introduction}

A suitable cage size that enables mink to move freely and rest is one of the factors that determine these animals' welfare. The appropriate keeping of animals in closed breeding system ought to meet all their physiological and behavioural needs (Mroczek, 2013), which ensures the proper growth and development of animals. Frequently, a too small surface area of cages may be the cause of the occurrence of aggressive stereotypical behaviour in mink, which may affect the growth and development of those animals. This kind of behaviour at first diminishes the animal's anxiety or distracts its attention from a negative stimulus, for example an aggressive individual in the cage or too small a cage. Subsequently, this kind of behaviour is repeated by the animal in an entirely uncontrolled manner in the form of futile movements, for example walking around the diameter of the cage, chasing its own tail, and licking the wire mesh, all of which are physically exhausting (Damgaard et al., 2004; Kiley-Worthington, 1995; Toates, 1995; Mason, 1991). According to numerous studies, diversification in mink keeping influences the frequency of stereotypic behaviour occurrence (Jeppesen et al., 2000; Vinke et al., 2004; Pedersen et al., 2004). Increasing the size of the cage's surface area improves the animals' comfort of living. It enables them to move around freely and provides them with extra space for resting or even hiding from another animal. Such conditions favour the proper behaviour of animals and may be beneficial in terms of bodyweight gains. On the other hand, mink that have more space to move around and for example jump from one storey to another may lose bodyweight more rapidly and obtain lower daily weight gains. Nevertheless, the literature does not state whether a larger surface area negatively affects the final bodyweight of mink and their daily bodyweight gains and, consequently, the length of hides. According to Lohi \& Hansen (1990), there is a positive correlation between bodyweight and the length of hides. It is vital then for farms to keep mink of higher bodyweight to obtain hides of the largest possible size.

The adopted hypothesis was that the difference in cage size affects the volume of bodyweight and mean daily bodyweight gains in mink. 


\section{Material and Methods}

The study was conducted in 2014 and 2015 at a private mink farm in Poland. In total, 800 brown mink were used, including 400 males (200 animals in 2014, and 200 in 2015) and 400 females (200 animals in 2014, and 200 in 2015). The kits that were assessed over a two-year period came from the same dams. The influence of the father was hard to determine since mink mated two or three times with different males. The animals were all fed the same food, depending on maintenance requirements in breeding periods determined according to feeding standards (Gugołek, 2011). Each year during the study period, the mink were divided into two groups, depending on the housing system. The first group included 400 animals in single-storey cages (200 in 2014 and 200 in 2015), and the second group of 400 animals (200 in 2014 and 200 in 2015) were kept in two-storey cages, meaning cages with an added storey, where they could move freely between the lower and upper storeys. The cages were of the 'Dutch' variety, with the single-storey cage dimensions of $92 \mathrm{~cm} \times 32 \mathrm{~cm} \times 45 \mathrm{~cm}(\mathrm{~L} \times W \times \mathrm{H})$, and two-storey cage dimensions of $92 \mathrm{~cm} \times 32 \mathrm{~cm} \times$ $45 \mathrm{~cm}$ on the lower storey and $63.5 \mathrm{~cm} \times 32 \mathrm{~cm} \times 45 \mathrm{~cm}$ on the upper storey. There were nesting boxes with substrate in each cage. The nesting boxes were made of $18 \mathrm{~mm}$ hard particle board, were lined with straw, and were fixed to the front of the cage. Animals were divided into groups according to their previous type of cage. In this way, those that had been kept all their lives in single-storey cages were assigned to singlestorey cages, while those born in two-storey cages were put into two-storey cages. The animals were weighed twice: after weaning (week 7 of their lives) and prior to slaughter (at the age of approximately 7 months) on an electronic scale.

Based on data concerning bodyweights, daily gains in mink were calculated using this formula:

$$
P=\frac{M c_{2}-M c_{1}}{D}
$$

where: $P=$ daily bodyweight gains

$M c_{1}=$ bodyweight at weaning

$\mathrm{Mc}_{2}=$ pre-slaughter bodyweight

$D=$ number of days from weaning to slaughter

Statistical characteristics were prepared for these traits by calculating the arithmetic mean and the standard deviation. This was followed by using the fixed effects model (GLM) to calculate the analysis of variance based on a crossed model with an interaction. These effects were included in the model: sex and cage type.

$$
y_{i j}=\mu+a_{i}+\beta_{j+}(a \beta)_{i j}+e i j
$$

where: $y_{i j k}=$ weaning bodyweight, pre-slaughter bodyweight, daily bodyweight gains

$\mu=$ mean total value

$a_{l}=\mathrm{i}$ sex effect

$\beta_{j}=\mathrm{j}$ cage type effect

$a \beta_{i j}=$ the effect of interaction between factors

$e_{i j}=$ random error

To verify the significance of differences between sex and cage type subgroups, Scheffé's test was applied. Furthermore, the Pearson correlation coefficient was calculated to estimate correlations between the analysed traits (Kot et al., 2011). All calculations were conducted using Statistica PL.9.0 data analysis software (StatSoft Inc. STATISTICA).

\section{Results}

Table 1 presents the results of bodyweight in mink at weaning and prior to slaughter, and their daily gains, depending on the housing system and sex. It was observed that in both years the bodyweight in male animals kept in two-storey cages was slightly higher at weaning (811 g in 2014 to $820 \mathrm{~g}$ in 2015) than males from single-storey cages (781 g to $788 \mathrm{~g}$, respectively); however, the differences were not confirmed statistically. In females, the mean bodyweight at weaning was similar regardless of cage type, namely 634$630 \mathrm{~g}$ (group I); and 614-621 g (group II). When pre-slaughter bodyweight and daily bodyweight gains were analysed in females both and males, no significant differences were found between the results of animals from the first and second group. However, their values differed statistically depending on $\operatorname{sex}(P \leq 0.01)$. 
Table 1 Mean $(\stackrel{\overline{\mathbf{x}}}{\overline{\underline{x}}})$ and standard deviation (Sd) for weaning bodyweight and pre-slaughter bodyweight and mean daily gain in mink

\begin{tabular}{|c|c|c|c|c|c|c|}
\hline \multirow[b]{2}{*}{ Years } & \multirow[b]{2}{*}{ Cage type } & \multirow[b]{2}{*}{ Sex } & \multirow[b]{2}{*}{$\mathrm{N}$} & $\begin{array}{l}\text { Weaning bodyweight } \\
\text { (grams) }\end{array}$ & $\begin{array}{l}\text { Pre-slaughter bodyweight } \\
\text { (grams) }\end{array}$ & $\begin{array}{l}\text { Bodyweight daily gains } \\
\text { (grams) }\end{array}$ \\
\hline & & & & $\frac{\bar{x}}{\mathrm{x}} / \mathrm{Sd}$ & $\frac{\overline{\mathrm{x}}}{\mathrm{x}} / \mathrm{Sd}$ & $\frac{\overline{\mathrm{x}}}{\overline{\mathrm{B}}} / \mathrm{Sd}$ \\
\hline \multirow{6}{*}{2014} & \multirow{3}{*}{$\begin{array}{l}\text { Single-storey } \\
\text { cages }\end{array}$} & $\hat{\sigma}$ & 100 & $781.0^{\star \star} \pm 104.9$ & $2965.0^{\star *} \pm 371.5$ & $16.8^{\star \star} \pm 3.8$ \\
\hline & & q & 100 & $634.0^{\star \star} \pm 83.4$ & $1646.0^{\star \star} \pm 249.4$ & $7.8^{\star \star} \pm 2.3$ \\
\hline & & Total & 200 & $713.0 \pm 120.4$ & $2353.0 \pm 740.7$ & $13.5 \pm 5.3$ \\
\hline & \multirow{3}{*}{$\begin{array}{l}\text { Two-storey } \\
\text { cages }\end{array}$} & $\hat{\sigma}$ & 100 & $811.0 * \star \pm 153.1$ & $3018.1^{* \star} \pm 197.2$ & $17.0 * \star \pm 1.1$ \\
\hline & & q & 100 & $614.5^{\star \star} \pm 73.7$ & $1603.4^{* *} \pm 138.6$ & $7.6^{\star \star} \pm 1.8$ \\
\hline & & Total & 200 & $720.9 \pm 157.3$ & $2369.3 \pm 727.6$ & $12.7 \pm 4.9$ \\
\hline \multirow{6}{*}{2015} & \multirow{3}{*}{$\begin{array}{l}\text { Single-storey } \\
\text { cages }\end{array}$} & $\hat{0}$ & 100 & $778.0^{\star \star} \pm 98.2$ & $2974.4^{\star \star} \pm 212.6$ & $17.2^{\star \star} \pm 3.2$ \\
\hline & & q & 100 & $630.5^{\star \star} \pm 83.3$ & $1648.0^{\star \star} \pm 122.3$ & $7.9^{\star \star} \pm 2.3$ \\
\hline & & Total & 200 & $711.5 \pm 128.2$ & $2358.2 \pm 683.4$ & $13.2 \pm 5.1$ \\
\hline & \multirow{3}{*}{$\begin{array}{l}\text { Two-storey } \\
\text { cages }\end{array}$} & $\hat{\sigma}$ & 100 & $820.8^{\star \star} \pm 106.7$ & $3023.2^{\star \star} \pm 201.6$ & $16.9 * \star \pm 1.9$ \\
\hline & & q & 100 & $621.6^{\star \star} \pm 79.7$ & $1610.0^{\star \star} \pm 99.5$ & $7.7^{\star \star} \pm 1.5$ \\
\hline & & Total & 200 & $714.2 \pm 126.3$ & $2363.2 \pm 315.6$ & $13.6 \pm 4.9$ \\
\hline
\end{tabular}

**significant differences between individuals of different sexes within the researched groups

Lack of significant differences between researched groups

Pre-slaughter male bodyweight was observed to be within the range of $2970 \mathrm{~g}$ (single-storey cages) to over $3000 \mathrm{~g}$ (two-storey cages), while in females, regardless of the housing system, weight was over $1600 \mathrm{~g}$. Daily bodyweight gains, no matter which type of cage was used, had the mean value of $17 \mathrm{~g}$ in males and $7 \mathrm{~g}$ in females. Table 2 indicates that there was no interaction between sex and cage type with respect to mean bodyweight gains. The study revealed a significant effect of sex on pre-slaughter bodyweight $(P \leq 0.01)$ and mean bodyweight gains $(P \leq 0.01)$. No significant effect of the cage type on the above traits was established (Tables 1 and 2).

Table $2 \mathrm{~F}_{\mathrm{emp}}$ value and the significance of the cage type and sex effect on pre-slaughter bodyweight, and daily bodyweight gain in brown mink

\begin{tabular}{lcc}
\hline Factor & $\begin{array}{c}\text { Pre-slaughter bodyweight } \\
\mathrm{F}_{\mathrm{emp}} / \mathrm{p}\end{array}$ & $\begin{array}{c}\text { Daily bodyweight gain } \\
\mathrm{F}_{\mathrm{emp}} / \mathrm{p}\end{array}$ \\
\hline Sex & $236.4 / 0.0001$ & $1547.6 / 0.0001$ \\
Cage type & $0.001 / 0.985$ & $0.002 / 0.967$ \\
Sex * cage type & $0.58 / 0.447$ & $0.57 / 0.447$ \\
\hline
\end{tabular}

Based on correlation coefficients, relationships between bodyweight at weaning and pre-slaughter bodyweight and mean bodyweight gains were estimated for each sex separately. In both males and females, a strong correlation was found between pre-slaughter bodyweight and daily gains: $r_{\mathrm{xy}}=0,92 \hat{\jmath} ; 0,94 \stackrel{+}{ }(P$ $<0,001)$. Considerably lower correlation was found between kits' bodyweight at weaning and mean gains. However, in this case the correlation coefficient was negative for both sexes: $r_{\mathrm{xy}}=-0.42{ }^{2} ;-0.25(P<0.001) q$ (Figures 1 and 2). 


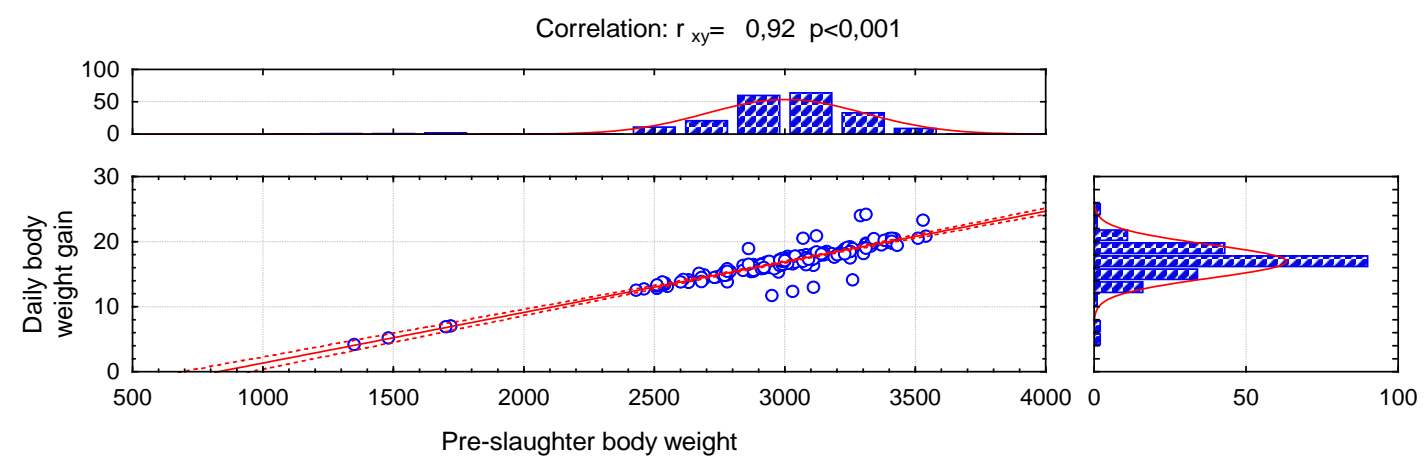

口
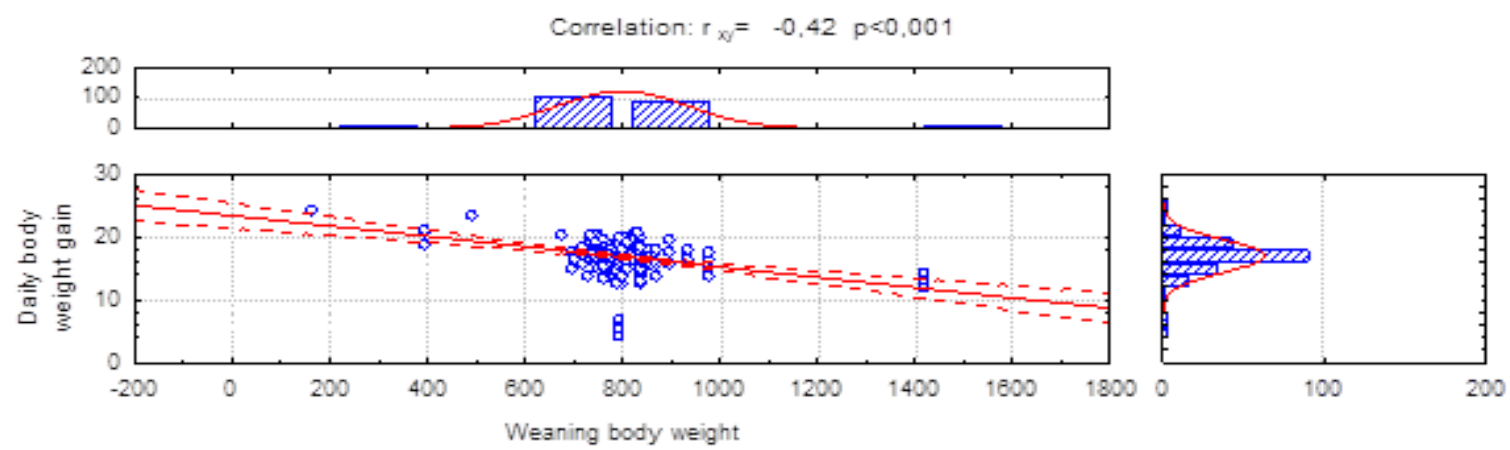

Figure 1 Pearson correlation coefficient for the traits of weaning bodyweight, pre-slaughter bodyweight the male and daily gain in mink

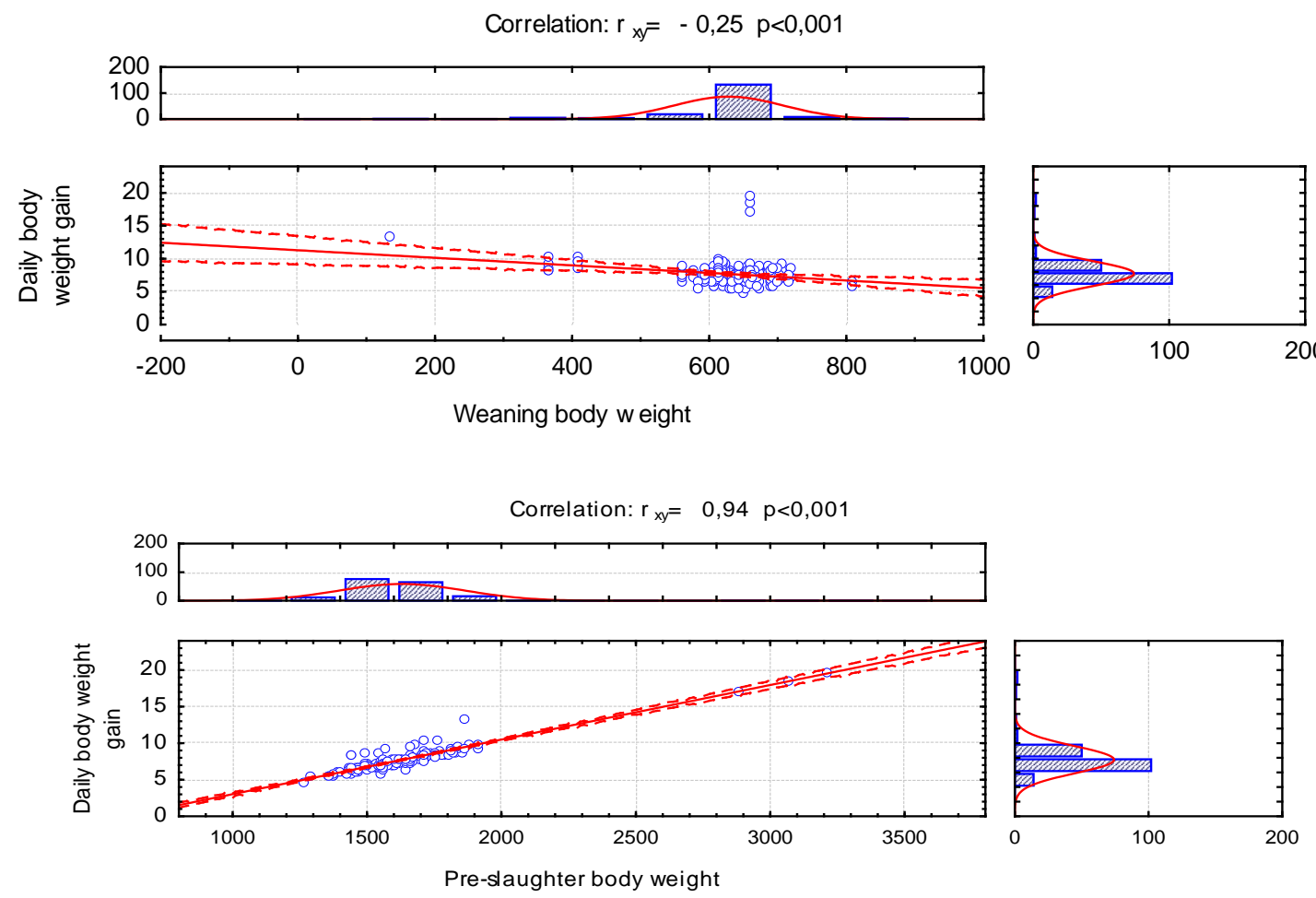

Figure 2 Pearson correlation coefficient for the traits of weaning bodyweight, pre-slaughter bodyweight in females and daily gain in mink 


\section{Discussion}

As the conclusion of the in-house research indicated, the sizes of cages do not have any significant influence on the results concerning daily bodyweight gains. It was observed that mean daily bodyweight gains remained at an equal level in both groups, males and females, and were approximately $17 \mathrm{~g}$ and $8 \mathrm{~g}$, respectively The study did not find any significant effect of cage size on pre-slaughter bodyweight results or daily bodyweight gains (Table 1 and Table 2). Similar results were obtained by Hansen et al. (2007), who showed that bodyweight gains of males, and females, do not depend on the size of the cage in which the animals are kept. The in-house research indicated significant differences between sexes. Hansen et al. (2007) also observed that the values of the studied features are diversified depending on the sex, which is the result of strongly developed sexual dimorphism in those animals. In the analysis of bodyweight prior to slaughter, it was observed that it was approximately 35\% higher in males than in females. Bodyweight of males in that period was approximately $3000 \mathrm{~g}$. Females were lighter and their bodyweight amounted to $1600 \mathrm{~g}$ (Table 1). According to other authors, bodyweight in mink before slaughter, both male and female, was approximately $2000 \mathrm{~g}{ }^{\dagger}$ and $1200 \mathrm{~g}$ + (Bielański et al., 2005; Piórkowska et al., 2004; Piórkowska et al., 2014; Pölönen et al.,1999). According to Nurominen \& Sepponen (1996), mink growth stops in midSeptember and further intensive feeding of animals has minimal impact on the final length of their hides. The in-house research assumed that a larger surface area of cages gives the animals an opportunity to move and thus may cause increased energy consumption, resulting in lowering the animals' bodyweight. However, larger space and low density of animals might result in increased use of energy for maintaining sufficient body temperature compared with those mink that were kept in single-storey cages, where animals remained in close contact. According to Tauson et al. (2006), mink kept in groups, that is, in higher density, accumulated less subcutaneous fat than those kept in pairs, since they did not need to use so much energy to maintain proper body temperature. The in-house research indicated only slight differences in bodyweight gains. The difference in cage size for the two researched groups might have been too small to be able to observe this relationship. Lack of significant differences in bodyweight and mean bodyweight gains between the researched groups is therefore proof that single-storey and two-storey cages fulfil the requirements of welfare of mink. However, slightly higher bodyweight prior to slaughter and daily gains in males kept in twostorey cages were observed during in-house research. Similarly, Szendro et al. (2009) showed that rabbits kept in cages with a larger surface area had higher bodyweight gains. It is likely that in two-storey cages those animals were able to keep at a distance from one another and could flee onto the upper level of the cage which could diminish the level of stress and contribute to the slightly higher results. Mink, because of being kept in pairs in cages, are particularly exposed to so-called social stress. It occurs in such situations as territorial conflict and rivalry in the same hierarchy (Kaleta, 2009). Long-term exposure to stress may be the cause of many behavioural disorders, as a result of which animals may lose weight for example because of excessive agitation, as with stereotypical behaviour and loss of appetite in a state of depression (Gulevich et al., 2000; Hansen et al., 1994; Hansen, 2006; Hansen et al., 2007, Hänninen et al., 2008a; Jeppesen et al., 2004; Kokocińska \& Kaleta, 2016). It is difficult to assess whether that was the reason because the object of the research did not include behavioural observation of animals.

Additionally, the in-house research showed a strong correlation between bodyweight prior to slaughter and daily bodyweight gains. Positive correlation of these two features was determined $\mathrm{r}_{\mathrm{xy}}=0,92 \lambda ; 0,94$ \% $(P$ $<0,001$ ) (Charts 2 and 3). This indicates that large mean daily bodyweight gains result from high final bodyweight of animals prior to slaughter. Considerably weaker and negative correlations were noticed between bodyweight at weaning and daily bodyweight gains in the current study. According to Lagerkvist et al. (1994), the bodyweight of animals accompanied by mothers until weaning results mainly from litter size from which offspring come from and from mothers' lactation. It is probable that the free access to solid food and less competition for food enabled the animals to meet their individual needs.

\section{Conclusions}

To sum up, the adopted hypothesis, which stated that varied cage area affects bodyweight and daily gains in both male and female mink, was rejected, since the authors did not observe significant differences between the analysed groups, which were kept in different conditions. Statistically significant differences were observed in animals of both sexes. Males had much higher pre-slaughter bodyweight and higher gains than females. No interaction was found between the cage type and the sex of the animals.

\section{Acknowledgements}

Research carried out within statutory research Division Breeding Sheep, Goats and Fur Animal BS-7/2013. The authors thank farmers for allowing the experiment and cooperation during the research

\section{Authors' Contributions}

NŚ collection of data, preparation of statistical and work. HB data collection and evaluation work 


\section{Conflict of Interest Declaration}

The authors declare that they have no conflicts of interest with regard to this work.

\section{References}

Bielański, P., Piórkowska, M. \& Zoń, A., 2005. The effect of mink genotype on selected breeding performance indicators and coat quality. Rocz. Nauk. PTZ 3, 423-430 (in Polish).

Broom, D.M. \& Johnson, K.G., 1993. Stress and animal welfare. Chapman \& Hall, London, UK.

Council of Europe 2001. The welfare of animals kept for fur.Report of the Scientific Committee on Animal Health and Animal Welfare Adopted on 12-13 December.

Damgaard, B.M., Hansen, S.W., Børsting, C.F. \& Møller, S.H., 2004. Effects of different feeding strategies during the winter period on behaviour and performance in mink females (Mustela vison). Appl. Anim. Behav. Sci. 89,163180.

Gugołek, A., (ed.) 2011. Nutritional recommendations and nutritive value of feeds in fur animals. Jabłonna (in Polish).

Gulevich, R.G., Kharlamowa, A.V. \& Trapezov, O.V., 2000. Behawioral traits and adrenal function in mink selected for tameness and aggressiveness. Scientifur. 4, 139-142.

Hansen, S.W., 2006. Giv minken noget at rive, bide og flå i, Dansk Pelsdyravl 8, 28-29.

Hansen, S.W., Hansen, B.K. \& Berg, P., 1994. The effect of cage environment and ad libitum feeding on the circadian rhythm, behaviour and feed intake of farm mink. Acta. Agr. Scand. A-An. 44, 120-127.

Hansen, S.W., Malmkvist, J., Palme, R. \& Damgaard, B.M., 2007. Do double cages and access to occupational materials improve the welfare of farmed mink? Anim. Welf. 16, 63-76.

Hänninen, S., Ahola, L., Pyykönen, T., Korhonen, H.T. \& Mononen, J.,2008. Group housing in row cages: an alternative housing system for juvenile mink. Animal. 2, 1809-1817.

Hänninen, S., Mononen, J., Harjunpää, S., Pyykönen, T., Sepponen, J. \& Ahola, L., 2008a. Effects of family housing on some behavioural and physiological parameters of juvenile farmed mink (Mustela vison). Appl. Anim. Behav. Sci. 109, 384-395.

Jeppesen, L.L., Heller, K.E. \& Bildsøe, M., 2004. Stereotypies in female farm mink (Mustela vison) may be genetically transmitted and associated with higher fertility due to effects on bodyweight. Appl. Anim. Behav. Sci. 86, 137-143.

Jeppesen, L.L., Heller, K.E. \& Dalsgaard, T., 2000. Effects of early weaning and housing conditions on the development of stereotypies in farmed mink. Appl. Anim. Behav. Sci. 68, 85-92.

Kiley-Worthington, M. 1995. Animals in circuses and zoos: Chiron's world? Little Eco-Farms Publishing, Essex.

Kaleta, T., 2009. Stres i zachowanie się zwierząt dzikich - badania i interpretacje. Życie Wet. 84 (1), 21-26. (in Polish)

Kokocińska, A. \& Kaleta, T., 2016. Znaczenie etologii w naukach o dobrostanie zwierząt, Rocz. Nauk. PTZ, 12 (1), 49-62 (in Polish).

Kot, S.M., Jakubowski, J. \& Sokołowski, A., 2011. Statistics. Wyd. Difin. (in Polish).

Lagerkvist, G., Johansson, K. \& Lundeheim, N., 1994. Selection for litter size, bodyweight and pelt quality in mink (Mustela vison). Correlated responses. J. Anim. Sci. 72, 1126-1137.

Lohi, O. \& Hansen, B.K., 1990. Heritability of body length and weight in mink, and the effects of time of birth and litter size on growth. Nordisk Jordbrugs Forskning. 72,128.

Nurominen, L. \& Sepponen, J., 1996. Effect of fattening on skin length of farmed mink. Zesz. Nauk. Przegl. Hod. 29, 159165.

Mason, G., 1991. Stereotypes: A critical review. Anim. Behav. 41, 1015-1037.

Mroczek, J.R., 2013. Animal welfare as a retarding factor of resource transformation in animal production. Inż. Ekol. 34, 181-188 (in Polish).

Pedersen, V., Jeppesen, L.L. \& Jeppesen, N., 2004. Effects of group housing systems on behaviour and production performance in farmed juvenile mink (Mustela vison). Appl. Anim. Behav. Sci 88, 89-100.

Piórkowska, M., Bielański, P. \& Zoń, A., 2004. Effect of mink breeding conditions on body mass and skin size parameters. Ann. Anim. Sci. 1, 339-342.

Piórkowska, M., Kowalska, D. \& Zoń, A., 2014. The effect of increasing the number of animals in a cage on coat quality in mink. Rocz. Nauk Zoot. 41, 51-63 (in Polish).

Pölönen, I., Niemelä, P., Jalkanen, L., Korhonen, H. \& Mäkelä, J., 1999. Formic acid-sodiumbenzoate preserved slaughterhouse offal and supplementary folic acid in mink diet. Anim. Feed Sci. Technol. 78, 39-56.

Report of the Scientific Committee on Animal Health and Animal Welfare, 12 December 2001. Scandinavica, Section A; Anim. Sci. 44, 120-127.

StatSoft Inc STATISTICA (data analysis software system), version 9.0., 2009. (Available from: www.statsoft.com).

Szendro, Z.S., Princz, Z., Romvári, R., Locsmándi, L., Szabó, A., Bázár, G., Radnai, I., Biró-Németh, E., Matics, Z. \& Nagy. I., 2009. Effect of group size and stocking density on productive, carcass, meat quality and aggression traits of growing rabbits. WRSA 17, 153-162.

Tauson, A.H., Chwalibog, A. \& Tygesen, M.P., 2006. Late development of homeothermy in mink (Mustela vison) kits - a strategy for maximum survival rate. J. Anim. Physiol. AN N. 90, 34-45.

Toates, F., 1995.Stereotypes. In: F. Toates (ed.) 1995. Stress/conceptual and biological aspects. John Wiley \& Sons, Chichester, 215-151.

Vinke, C.M., Bos van den, R. \& Spruijt, B.M., 2004. Anticipatory activity and stereotypical behaviour in American mink (Mustela vison) in three housing systems differing in the amount of enrichments. Appl. Anim. Behav. Sci. 89 145161. 